\title{
A Review of the Effectiveness and Boundary Conditions of Leader Humility
}

\author{
Shuang Xu \\ The College of Management, Jinan University, Guangzhou, China \\ Email: shxtwins@163.com
}

How to cite this paper: $\mathrm{Xu}, \mathrm{S}$. (2019) A Review of the Effectiveness and Boundary Conditions of Leader Humility. Journal of Service Science and Management, 12, 234-245.

https://doi.org/10.4236/jssm.2019.122016

Received: January 22, 2019

Accepted: February 24, 2019

Published: February 27, 2019

Copyright $\odot 2019$ by author(s) and Scientific Research Publishing Inc. This work is licensed under the Creative Commons Attribution International License (CC BY 4.0).

http://creativecommons.org/licenses/by/4.0/

\begin{abstract}
In recent years, top-down leadership style such as humility has received widespread attention in academic and practical areas. Although theoretical and empirical studies have shown that the humble leadership has a positive impact, it lacks systematic review of its mechanism and the research about boundary conditions of its positive impact. The article begins with a brief overview of the research status of humble leaders, and then combs the study of the boundary conditions of the humble leadership when it comes to individual and group levels. Finally, the future research is proposed.
\end{abstract}

\section{Keywords}

Leader Humility, Leadership Effectiveness, Boundary Conditions

\section{Introduction}

The rapid development of today's information society, information explosion and diversification of capabilities makes it difficult for leaders to effectively face market competition and make effective corporate decisions based on their individual knowledge and capabilities. In corporate practice, arbitrariness, arrogance, and arrogant leadership have had many adverse effects on the company such as scandals [1] [2]. Business managers urge leaders to demonstrate more humility, to take advantage of their subordinates, to improve their overall competitiveness, to face changes in external markets and to promote business development. Humble leadership means having a more accurate self-concept, being able to recognize its own weaknesses and shortcomings, being good at listening to suggestions, and being good at discovering the strengths and contributions of others, and showing leadership style that respects colleagues [3].

From the existing research in the field of histology, scholars still have controversy about the effectiveness of humble leadership. Although the positive influ- 
ence of the humble leadership in the organization has initially received theoretical and empirical support, some scholars still believe that the humbleness of leadership can not only bring positive effects, but also lead the subordinates to lead [4]. Weak cognition leads to doubts and resistance to leadership decisions and orders. Therefore, we need to further explore and clarify the boundary conditions for the positive influence of humble leaders. On the one hand, we will sort out the influence of humble leaders, and on the one hand, it can answer the question of how leaders can produce positive effects in the context of the new era. This article will start from the individual results of the humble leadership and the group results, and sort out their boundary conditions. The individual level mainly includes four aspects: leadership factors, subordinate factors, external situation factors and interaction relationships; the group level mainly includes organizational situation factors and group perception factors.

The article is organized as follows: First, the article briefly describes the effectiveness of humble leaders. The positive influence of humble leaders is mainly on individual employees and teams or organizations. Secondly, it introduces the theoretical basis and research perspective based on the humble leadership's proposed boundary conditions, then based on the individual results and group results, summarizes its boundary conditions or adjustment factors. The moderators of individual results are divided into the subordinate factors, leader factors, interactions, and organizational factor. The moderators of group results include subordinates' perception of the group and organizational situational factors. Finally puts forward the research shortage and prospects for the future.

\section{The Effectiveness of Humble Leadership}

\subsection{Individual Level}

The outcome variables of humble leadership are mainly concentrated at the individual level. Humble leadership can improve subordinates' performance [3], job satisfaction [5], and promote subordinate organization identification, work input [6], reduce employee turnover intention, improve creativity and individual innovation behavior [7], improve employee behavior and reduce silence [8]; increase employee initiative change behavior and reduce feedback avoidance behavior; promote employee organizational citizenship behavior [9]. Greenleaf et al. (2002) and De Cremer (2009) found that bottom-up leadership can increase subordinate loyalty and thus improve organizational financial performance. Nielsen et al. (2010) suggest that humble leaders can significantly improve subordinates' self-efficacy. The results of Owens (2012) show that humble leaders can enhance the work input of their subordinates.

\subsection{Group Level}

Relative to the results at the individual level, there are relatively few studies on the effectiveness of humble leaders at the team level and the organizational level. The team-level outcome variables are mainly team creativity and team effective- 
ness. Empirical studies have shown that humble leaders improve the team learning atmosphere, employees share knowledge and improve team effectiveness. Craham (1991) and Spears (1998) show that "bottom-up" leadership, such as public servant leadership, helps improve the financial performance of the team; Vera and Rodriguez-Lopez (2004) suggest that humble leaders create a good learning atmosphere. An open attitude towards new knowledge and ideas, with a unique competitive advantage, can effectively enhance the creativity of the team [10]. By building a community of ideas to improve team learning and team innovation, the group's humility can promote team performance.

In addition, at the organizational level, humble CEOs can also promote organizational innovation, optimize corporate performance, and optimize corporate innovation models through empowerment and integration of executive teams [11].

\section{Research Perspective and Theoretical Basis}

The combined with the existing literature, the moderator's adjustment variables are mainly studied from the perspectives of leadership change, human-contextual interaction, complementary coordination theory and trait activation theory, and social information processing theory. Among them, there are many theoretical perspectives at the individual level. The effectiveness of humble leaders at the team level is mostly from the perspective of social information processing.

According to the theory of leadership change theory, there is no universally applicable leadership style or leadership style. The effectiveness of leadership style is inevitably affected by situational factors, as is the humble leadership behavior. Although humble leadership behavior is considered to have a positive impact on organizations and individuals in many aspects, its effectiveness is constrained by some contextual factors, such as the right distance, tradition, and relative deprivation.

The theory of interaction between people and situations believes that individuals and situations are an integrated, complex and dynamic system that emphasizes the interaction between people and situations and the role of context in individual function and development, the impact of humble leadership on employees and organizations. It is also subject to situational factors, such as individual power distance [12]. Employees with different proactive personalities may face individual differences in their response to humiliating leadership. Individuals with stronger active personality are more likely to improve their situation or create a more favorable situation for themselves according to the characteristics of the situation in the face of important situations such as the leader's behavioral style.

From the perspective of complementary coordination theory, when the leader's behavior or ability is in the scope of the employee's needs, the corresponding leadership ability and behavior will play a significant role; on the contrary, when the leader's behavior or ability is less in the scope of the employee's need The 
role of leader's ability or behavior will be relatively weak. Related researchers propose organizational support perception as a regulatory variable based on complementary coordination theory. The theory of trait activation suggests that the impact of the environment on employees will vary depending on individual differences in employees [13]. Faced with the same leadership style or behavior, subordinates of different traits may have very different responses.

According to the social information processing theory, from the perspective of employees' social information processing process of leadership behavior, employees' interpretation of leadership behavior will affect the acceptance and recognition of employees' leadership behavior, and thus affect the effectiveness of humble leaders. According to the social information processing theory proposed by Salancik and Pfeffer, people will judge the social situation in which they are located, and then adjust the corresponding attitudes and behaviors [14]. Social contexts can not only help individuals construct and understand the meaning of events occurring in their environment, but also "indirectly" focus their attention on specific information to help them adjust their attitudes and behaviors. Leadership is an important social context in a team work environment. Leaders' attitudes and behaviors will provide important social clues to team members to make judgments about the external environment and adjust their attitudes and behaviors. Because the humble leaders in the team will also influence the effectiveness of the team by promoting the team to generate a certain atmosphere or values, and driving the team members to produce certain behaviors to influence the team interaction mode.

\section{Boundary Conditions of Humble Leadership on Individual Results}

In an organizational environment, the influence of leadership behavior on the individual level is constrained by individual characteristics and contextual factors. The subordinate factors, leader factors, interactions, and organizational factor are used to sort out the variability of humble leadership on individual outcomes.

\subsection{Subordinate Factor}

The leadership style has different effects on subordinates of different attributes and traits. So subordinate factors such as traits will affect the effect of humble leadership.

1) Traditional

Yang Guoshu (1991) proposed that tradition is the most common set of organized ideas, cognitive attitudes, value orientations, temperament characteristics and behavioral intentions of individuals in traditional society. As an important reflection of differences in individual values, traditionality has an important impact on employee behavior. When employees are highly traditional individuals, they are willing to follow the instructions of the leaders to complete their duties. 
Being granted autonomy will make them feel painful and at a loss, thus inhibiting the occurrence of innovative behavior [15]. When employees are low-classic individuals, the good leadership-employee relationship and high degree of autonomy created by humble leadership behavior enable subordinates to enhance their awareness of the identity of the people within the organization, thereby promoting work attitudes and inputs, and improving innovation behavior. That is, the higher the traditionalness of employees, the weaker the positive correlation between humble leadership behavior and individual innovation behavior, the lower the traditionalness of employees, and the stronger the positive correlation between humble leadership behavior and individual innovation behavior.

\section{2) Adjustment focus}

Higgins believes that individuals have two sets of regulatory systems: defensive adjustment focus and promotion regulation focus. Individuals with defensive adjustment focus on duties, responsibilities, and safety; individuals who promote focus adjustment focus on hope, development, and success, and the more prominent the defensive adjustment tendency of employees, the stronger the impact of humble leadership behavior on employee psychological safety; the more prominent the propensity to promote regulation, the stronger the impact of humble leadership behavior on employee self-efficacy [16].

3) Moderate thinking

Employees with higher moderation tend to take care of the overall situation, both internal and external, to maintain organizational harmony and stability, and to examine the impact of their actions on others, while employees with low-medium thinking usually do not consider the impact of their actions on the overall situation, even if leadership performance More humiliating behaviors, the moderate thinking negatively regulates the relationship between humble leaders and employees' restrained suggestions. The higher the middle-class thinking of employees, the weaker the positive correlation between humble leaders and restraining suggestions. Employee restraint suggestions can help improve the quality of decision-making, correct operational deviations, and improve management effectiveness [17]. The inhibitory suggestions of high-medium thinking employees will be less challenging and risky due to their behavior.

4) Power distance

Subordinate power distance refers to the degree to which subordinates accept and recognize the inequality of power distribution within the organization, and reflect the psychological characteristics of individual values. Studies have shown that the influence of humble leaders on subordinates' silent behavior, suggestive behavior, and subordinate creativity will be constrained by the contextual factors of subordinate power distance. The higher the sense of power of subordinates, the lower sense of leadership support behavior, the difficulty of forming good interaction with humble leaders, the weaker perception of leadership humble behavior, the weaker influence of humble leaders, the suppression of suggestions, feedback Seeking behaviors and other initiatives, employees' creativity is 
limited, and silent behavior is more [18] [19]. Low-power distance-oriented employees like equal subordinate relationships, have a strong sense of decision-making participation, and focus on an open and flexible work environment. When they perceive leadership support behavior, they will show more extra-role behavior.

5) Initiative personality

Active personality is a stable tendency of individuals to take active actions to influence the surrounding environment. It describes the unique adjustment methods of individuals actively improving their environment or creating a favorable new environment. Individuals with stronger active personality are more likely to improve their situation or create a more favorable situation for themselves according to the characteristics of the situation in the face of important situations (such as the leader's behavioral style). Some studies have pointed out that the stronger the active personality, the stronger the positive effect produced by humble leaders [20]. Zhang Juncheng et al. (2017) explored the relationship between humble leaders and employees, and found that active personality plays a positive role in regulating the humble leadership and employee behavior through the intermediary role of psychological security.

6) Employee independence self-construction

Self-construction is divided into independent self-construction and dependent self-construction. Markus (2001) believes that in the organization, independent self-constructed individuals will pay more attention to the inner thoughts, emotions and behaviors of the self, and the response to the situation is more based on how to express the internal quality and characteristics of the self. Compared with low-independence self-constructed employees, highly independent self-constructed individuals value self-inherent expression, are not obscured, are willing to demonstrate their abilities, and are willing to prove their abilities from actions and make a contribution [21]. Organizational change behavior, they will lead more active change behavior led by humble leaders. When individual independent self-construction is high, the positive influence of humble leaders on their active change behavior is more intense.

\subsection{Leader Factor}

1) Supervisor behavioral integrity

From the perspective of social information processing theory, the researchers suggest that leaders' words and deeds will also regulate the effect of humble leaders on employee opinions. When leaders and words are consistently high, the relationship between humble leaders and employees' opinions is strong. Supervisor behavioral integrity reflects the perception of the degree to which employees are consistent with what they say. From the perspective of employees' social information processing process of leadership behavior, the consistency of leadership and behavior will first affect the employee's goodwill interpretation of leadership behavior, which in turn will affect the acceptance and recognition of 
employee leadership behavior [5]. When employees' leaders and behaviors are consistently perceived, they will also have a higher level of recognition and trust for humble leaders, and employees will follow the leadership expectations and make more suggestions in the organization.

2) Leadership expertise

The behavior of honesty, self-sufficiency, appreciation and humility of the leadership will only become effective if the subordinates feel that the leader is capable and capable. The stronger the leadership ability, the higher the subordinate's recognition of the leader. It is easier to stimulate work enthusiasm and perform better work behavior [22].

3) Perceived leadership authority

From the perspective of subordinates, the higher the leadership authority perceived by the subordinates, the more convinced the leaders are, the more they can show a better working attitude and work behavior, and the positive influence of humble leadership is greater [23]. If the leadership is humble, and the actual subordinates perceive the weak leadership, the negative influence is great.

\subsection{Interaction}

Ou, Qin, Chiu, and Owens et al. explored the regulatory effects of inconsistent status in cross-cultural research on the effectiveness of humble leadership. When a leader's social status is lower than a follower, in Chinese culture, this inconsistency can enhance the influence of humble leaders, because the followers' social status is higher than the leader may be more confident that their opinions will be Adoption [24], but considering that China is a country that respects high power distances and vertical collectivism, this phenomenon is not common in Chinese culture.

\subsection{Organizational Factor}

1) Task interdependence

Task interdependence plays a regulatory role in the relationship between humble leaders and the atmosphere of team building. When task interdependence is lower, the positive influence of humble leaders on the atmosphere of team building is greater. The higher the interdependence of tasks, the less positive the influence of humble leaders on the atmosphere of team building [25].

2) Work unit structure

In an organization, the structure of the work unit is an important contextual variable for leadership behavior, including mechanical and organic structures. Humble leaders are seen as supportive environments that meet the psychological needs of employees, while work unit structures are organizational contextual factors that influence the role of humble leadership. Being in an organic structure can provide a flexible and relaxed organizational environment for the humble leadership mechanism at the organizational level, and encourage employees to feel more "self" in their work; in the mechanical structure, emphasize strict 
Controlling and managing employees in accordance with the organization's existing rules and procedures, weakens the positive role of humble leaders in employee assessment and assessment, and causes employees to feel more sense of perseverance at work [26]. Thus, humble leaders have a stronger positive impact on employees in an organic structure.

\section{Boundary Conditions of Humble Leadership on Group Results}

In a team work environment, the influence of humble leaders on the group level is constrained by subordinate group perception and team external factors. The following is a summary of the adjustment variables of humble leadership effectiveness from two aspects: subordinates' perception of the group and organizational situational factors.

\subsection{Subordinates' Perception of the Group}

1) Relative deprivation of employees

Relative deprivation refers to the unhealthy psychological emotions caused by the comparison of unfairness [27]. Humble leaders carry out more solidarity and cultivating subordinates in their work, fully demonstrating the unique charm of leaders, and thus creating a work attitude towards employees positive influence. Relative deprivation plays a significant role in the relationship between humble leadership and turnover intention, mainly reflected in the higher relative deprivation, the weaker positive relationship between humble leadership and employee satisfaction; the higher the relative deprivation, the stronger the negative relationship between humble leadership and turnover intentions.

2) Team assigns a sense of fairness

Team-sharing fairness is the shared perception of the fairness of the results of each member of the team. Enhancing employee sense of fairness not only can effectively promote individual job satisfaction and organizational citizenship behavior, but also effectively promote organizational interaction processes such as team knowledge sharing and trust. Studies have shown that humble leadership behavior has a significant positive impact on team innovation [28]. In the case of high team fairness, team behavior integration mediates the relationship between humble leadership behavior and team innovation. Conversely, a lower sense of distributional justice can lead to negative effects such as individual emotional exhaustion and reduced work efficiency, thus curbing team development.

3) Team mental model

Based on social learning theory and social exchange theory, humble leaders have a positive predictive effect on employee feedback seeking behavior; team mental model has a significant adjustment effect on the relationship between team psychological security and employee feedback seeking behavior, when employees perceive The more perfect the team mental model is built, the stronger the positive effect of team mental safety on employee feedback seeking behavior 
[29]. The positive effect of humble leaders on employee feedback seeking behavior is stronger.

\subsection{Organizational Situational Factors}

1) Organizational performance

Because humble leaders take the initiative to take responsibility for the company's decision-making mistakes or low performance, Beauchesne and Hiller and other scholars suggest that humble leadership leads to a high turnover rate when organizational performance is poor or poorly managed. Humility leaders are frank and self-defeating and negligent [30]. They are easy to be amplified when organizational performance is poor, so that employees who are in a state of tension lose confidence in the leadership and give up following.

2) Organizational culture

In an organizational learning culture that encourages and reinforces learning, the effect of "modest learning" is more pronounced, and the effectiveness of humble leaders is stronger. Organizations that follow different levels, the humility of leaders will have different effects. Humble leadership can be humorous in organizations with low levels of hierarchy, and serious in organizations with high levels of hierarchy. For example, in the behavior of "appreciating the merits and contributions of subordinates", in organizations with low levels of hierarchy, leaders will praise all the advantages and contributions of subordinates, while in organizations with high levels of hierarchy, leaders only Praise some of the advantages and contributions of subordinates [31].

3) Extreme threats

Power threats and status threats make humble leaders in the face of threats to their own power, or subordinates over themselves, the positive impact on the team will be suppressed. And it is difficult to make correct decisions in time pressure. Too weak performance will cause employees to lose confidence [32]. When the company is facing difficulties, it is difficult for employees to convince the authority of leadership.

\section{Future Prospects}

- The Humble leadership team level results are less variable, and the theoretical perspective is single. The effectiveness of humble leadership focuses on the individual level, especially the positive impact of employees, and less on the effective boundary factors of teams and organizations.

- Empirical research on humble leadership explores the issue of the effect of regulating positive outcome variables. There are few empirical studies that have negative aspects of humility.

- Under the Chinese context, different corporate cultures and different levels follow the boundary conditions of leadership effectiveness.

- The effects of different levels of humble leadership lack empirical research. At present, most of them are at the level of direct leadership, and the lack of high-level humble leadership in China is effective. 


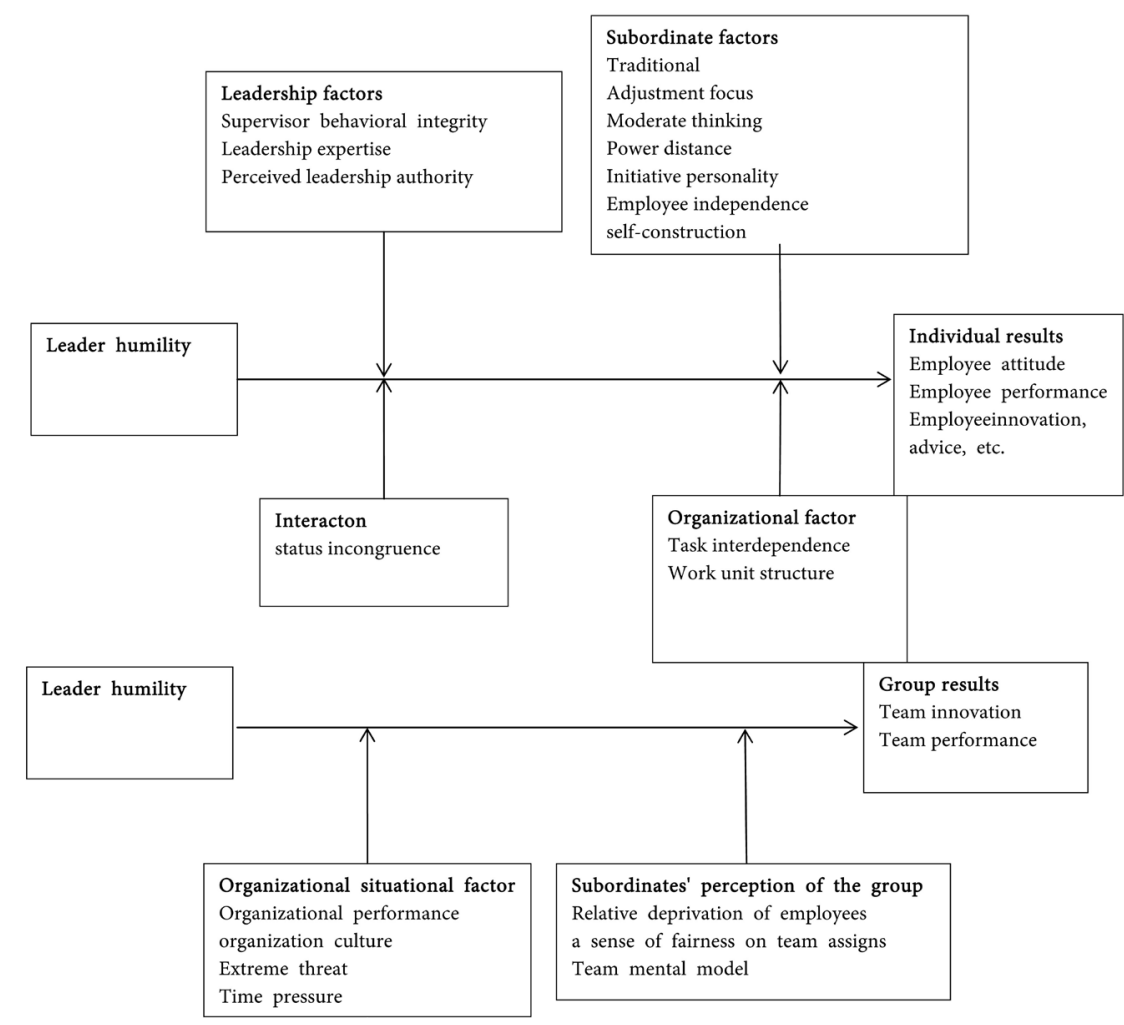

Figure 1. The moderators of leader humility on individual and group results.

- Considering the cultural differences, we need explore more applicability issues and tool development of humble leadership measurement in traditional Chinese culture. The measurement tools used by the humble leaders are mainly foreign scales. The leaders of Chinese enterprises are very unique in the collision of their traditional culture and modern culture, and can develop localized measurement tools.

Based on the above review of the effectiveness and boundary conditions of humble leadership, Figure 1 systematically demonstrates the regulatory factors of humble leadership from both individual results and group results.

\section{Acknowledgements}

Thanks to the authors of the articles cited in this article. Thanks for the support and help from my peers and tutors, they make it easier for me to access the information about this article.

\section{Conflicts of Interest}

The author declares no conflicts of interest regarding the publication of this paper.

\section{References}

[1] Boje, D.M., Rosile, G.A., Durant, R.A. and Luhman, J.T. (2004) Enron Spectacles: A Critical Dramaturgical Analysis. Organization Studies, 25, 751-774. 
https://doi.org/10.1177/0170840604042413

[2] Knottnerus, J.D., Ulsperger, J.S., Cummins, S. and Osteen, E. (2006) Exposing Enron, Media Representations of Ritualized Deviance in Corporate Culture. Crime, Media, Culture: An International Journal, 2, 177-195. https://doi.org/10.1177/1741659006065405

[3] Owens, B.P. and Hekman, D.R. (2012) Modeling How to Grow: An Inductive Examination of Humble Leader Behaviors, Contingencies, and Outcomes. Academy of Management Journal, 55, 787-818. https://doi.org/10.5465/amj.2010.0441

[4] Tangney, J.P. (2000) Humility: Theoretical Perspectives, Empirical Findings, and Directions for Future Research. Journal of Social and Clinical Psychology, 19, 70-82. https://doi.org/10.1521/jscp.2000.19.1.70

[5] Owens, B.P., Johnson, M.J. and Mitchell, T.R. (2013) Expressed Humility in Organizations: Implications for Performance, Teams, and Leadership. Organization Science, 24, 1517-1538. https://doi.org/10.1287/orsc.1120.0795

[6] Brickson, S. (2000) The Impact of Identity Orientation on Individual and Organizational Outcomes in Demographically Diverse Settings. Academy of Management Review, 25, 82-101. https://doi.org/10.5465/amr.2000.2791604

[7] Chancellor, J. and Lyubomirsky, S. (2013) Humble Beginnings: Current Trends, State Perspectives, and Hallmarks of Humility. Social and Personality Psychology Compass, 7, 819-833. https://doi.org/10.1111/spc3.12069

[8] Collins, J. (2001) Level 5 Leadership. The Triumph of Humility and Fierce Resolve. Harvard Business Review, 79, 66.

[9] Doty, J. and Gerdes, D. (2000) Humility as a Leadership Attribute. Military Review, 80, 89-90.

[10] Exline, J.J. and Geyer, A. (2004) Perceptions of Humility: A Preliminary Study. Self and Identity, 3, 95-115. https://doi.org/10.1080/13576500342000077

[11] Farh, J.L., Hackett, R.D. and Liang, J. (2007) Individual-Level Cultural Values as Moderators of Perceived Organizational Support-Employee Outcome Relationships in China: Comparing the Effects of Power Distance and Traditionality. Academy of Management Journal, 50, 715-729.

https://doi.org/10.5465/amj.2007.25530866

[12] Greenleaf, R.K., Spears, L.C., Covey, S.R. and Senge, P.M. (2002) Servant Leadership: A Journey into the Nature of Legitimate Power and Greatness. Paulist Press, New York.

[13] Hughes, L.W. (2010) Leadership under Pressure: Tactics from the Front Line. Leadership and Organization Development Journal, 31, 187-188. https://doi.org/10.1108/01437731011024439

[14] Knight, P.A. and Nadel, J.I. (1986) Humility Revisited: Self-Esteem, Information Search, and Policy Consistency. Organizational Behavior and Human Decision Processes, 38, 196-206. https://doi.org/10.1016/0749-5978(86)90016-6

[15] Means, J.R. and Wilson, G.L. (1990) Humility as a Psychotherapeutic Formulation. Counselling Psychology Quarterly, 3, 211-215. https://doi.org/10.1080/09515079008254249

[16] Morris, J.A., Brotheridge, C.M. and Urbanski, J.C. (2005) Bringing Humility to Leadership: Antecedents and Consequences of Leader Humility. Human Relations, 58, 1323-1350. https://doi.org/10.1177/0018726705059929

[17] Nielsen, R., Marrone, J.A. and Slay, H.S. (2010) A New Look at Humility: Exploring the Humility Concept and Its Role in Socialized Charismatic Leadership. Leadership 
\& Organizational Studies, 17, 33-43. https://doi.org/10.1177/1548051809350892

[18] Chiu, C.C., Owens, B.P. and Tesluk, P.E. (2016) Initiating and Utilizing Shared Leadership in Teams: The Role of Leader Humility, Team Proactive Personality, and team Performance Capability. Journal of Applied Psychology, 101, 1705.

[19] Oc, B., Bashshur, M.R., Daniels, M.A., Greguras, G.J. and Diefendorff, J.M. (2015) Leader Humility in Singapore. The Leadership Quarterly, 26, 68-80. https://doi.org/10.1016/j.leaqua.2014.11.005

[20] Ouimet, G. (2010) Dynamics of Narcissistic Leadership in Organizations: Towards an Integrated Research Model. Journal of Managerial Psychology, 25, 713-726. https://doi.org/10.1108/02683941011075265

[21] Ou, A.Y., Tsui, A.S., Kinicki, A.J., Waldman, D.A., Xiao, Z. and Song, L.J. (2014) Humble Chief Executive Officers' Connections to Top Management Team Integration and Middle Managers' Responses. Administrative Science Quarterly, 59, 34-72. https://doi.org/10.1177/0001839213520131

[22] Owens, B.P. and Hekman, D.R. (2016) How Does Leader Humility Influence Team Performance? Exploring the Mechanisms of Contagion and Collective Promotion Focus. Academy of Management Journal, 59, 1088-1111. https://doi.org/10.5465/amj.2013.0660

[23] Owens, B.P. and Wallace, A.S. (2015) Leader Narcissism and Follower Outcomes: Thecounterbalancing Effect of Leader Humility. Journal of Applied Psychology, 100, 1203-1213. https://doi.org/10.1037/a0038698

[24] Padilla, A., Hogan, R. and Kaiser, R.B. (2007) The Toxic Triangle: Destructive Leaders, Susceptible Followers, and Conducive Environments. Leadership Quarterly, 18, 176-194. https://doi.org/10.1016/j.leaqua.2007.03.001

[25] Paley, J. (2007) Kant and the Ethics of Humility: A Story of Dependence, Corruption and Virtue. Philosophy \& Phenomenological Research, 8, 139-141. https://doi.org/10.1111/j.1466-769X.2007.00263.x

[26] Vera, D. and Rodriguez-Lopez, A. (2004) Strategic Virtues: Humility as a Source of Competitive Advantage. Organizational Dynamics, 33, 393-408.

https://doi.org/10.1016/j.orgdyn.2004.09.006

[27] Wang, et al. (2017) Understanding How Leader Humility Enhances Employee Creativity-The Role of Perspective Taking and Cognitive.

[28] Resick, C.J., Whitman, D.S., Weingarden, S.M. and Hiller, N.J. (2009) The Bright-Side and the Dark-Side of CEO Personality: Examining Core Self-Evaluations, Narcissism, Transformational Leadership, and Strategic Influence. Journal of Applied Psychology, 94, 1365-1381. https://doi.org/10.1037/a0016238

[29] Podsakoff, N.P., Podsakoff, P.M., Mackenzie, S.B., Maynes, T.D. and Spoelma, T.M. (2014) Consequences of Unit-Level Organizational Citizenship Behaviors: A Review and Recommendations for Future Research. Journal of Organizational Behavior, 35, 87-119. https://doi.org/10.1002/job.1911

[30] Spiegel, J.S. (2003) The Moral Irony of Humility. Logos. A Journal of Catholic Thought and Culture, 6, 131-150. https://doi.org/10.1353/log.2003.0015

[31] Rowatt, W.C., Powers, C., Targhetta, V., Comer, J., Kennedy, S. and Labouff, J. (2006) Development and Initial Validation of an Implicit Measure of Humility Relative to Arrogance. Journal of Positive Psychology, 1, 198-211. https://doi.org/10.1080/17439760600885671

[32] Sandage, S.J. and Wiess, T.W. (2001) Contextualizing Models of Humility and Forgiveness: A Reply to Gassin. Journal of Psychology and Theology, 29, 201-211. https://doi.org/10.1177/009164710102900302 